five full-time professional staff and lay volunteers.

The move from hospital-based to community care will be further strengthened when the new day centres planned for Limassol and Paphos are opened. Mobile psychiatric clinics have been planned for the more remote areas of the island. However, a core of patients who were cared for by their families before the 1974 invasion are difficult to place since their families form part of the population of 200000 refugees created by the invasion. There are no known cases of homelessness since the commencement of the deinstitutionalisation programme. It is hoped that resistance to community care from within the mental health services will lessen once benefits to patients, staff and service become more evident with publication of recent research initiatives.

\section{Acknowledgements}

I am grateful to the Rt Hon Mr Manolis Christophides, Minister of Health, the Director of Mental Health Services, Dr Vassos Pyrgos, the Department of Statistics and Research and to the mental health service personnel for their time and support.

Marios Pierides, Research Registrar in Psychiatry, UMDS of Guy's and St Thomas', South Western Hospital Campus, Pulross Road, London SW9

\title{
The case of the vanishing boiler
}

\section{Ann Gath}

There has been a series of notorious hospital scandals from Ely to Ashworth involving gross neglect or abuse of vulnerable people who have been put away from the sight of the general public. Suddenly the spotlight is put on them and then the question is asked why no one has bothered before.

Sometimes it is possible to believe for a short period at least that such a thing could not possibly happen here - wherever that here may be. When the Observer produced its pictures of the hospital on Leros, that surely was beyond any local shortcoming.

Leros has two hospitals - the larger one caters for the mentally ill and for some adults with learning disability while the other, referred to as a children's hospital, caters for those with physical and severe developmental disability with ages ranging from 8 to 46 years, as no one was discharged. Many visitors from other European countries have been to Leros in the years since the Observer article. Strangely, those who visit the larger hospital, and they include a number of senior and respected members of the College, find that they are not able to visit the 'children's' part. It is the wrong time of day or unfortunately the director is away. Those who visit the 'children's' hospital, and they include me, find much the same with long waits outside committee rooms but then the meeting always continues after mid-day, the watershed for visits.

The initial visit to the children's hospital took place at the invitation of the team from Athens who were involved in a project aimed at improving the standards of care. On the flight to the island, we were accompanied by an extremely smartly dressed lady, whom we learnt was the chairman of the government organisation responsible for the institution. When we arrived we found the place scrupulously scrubbed and all the patients wearing new clothes - so new that the creases where they were folded were there in identical form on each. Beds were covered with brand new covers and their occupants lay still all facing the same direction. After the official visit was over, the new clothes all disappeared and once more excrement appeared on the floors.

The four wards, two upstairs and two downstairs, were all centred round the staircase beside which brooded a huge boller wheezing out vitriolic fumes. Everyone in the two upstairs wards had severe physical deformity and some had not been outside for years. There was no means of escape other than by the staircase. As well as being potentially poisonous and possibly explosive, the boiler was fickle and would suddenly pack up, usually in winter and often for months. The doctors in the team had studied the mortality over the previous winters and it 
became clear that the vagaries of the boiler had a relationship to the variation in deaths. There were many major problems on Leros and some seemed insoluble but here surely was a chance for a defined sum of money to do something concrete. The boiler must go.

A year later, back we went. In Athens, oh yes, the new boller was in place and working well. At the airport, well it was in place but not yet actually working (it was June). By the time the plane landed on Leros, the boiler had arrived at the institution but not yet been installed. On arrival at the institution, the information was that the order had gone astray. Then, inevitably, it was learnt that no order had been made and the funds had gone astray.

By contrast, there is a listed building surrounded by rhododendrons and azaleas, in a leafy suburb outside London. The occupants of the listed building are 24 old people who have spent almost all their lives in those huge old 'subnormality' hospitals, which because of the scandals referred to above, have closed. At each move, they each were separated from their friends about whom they got no further news. Now with the infirmity of old age added to years of deprivation, they have too few nurses to attend to their physical needs and their surroundings offer no dignity and no privacy. Throughout the autumn water drips from the ceiling and seeped through the walls. Even the Director of Quality has never been to see them. The lecturer from the Poly got $£ 26,000$ from region to audit the residential services for people with learning disability. She never got as far as them, despite the fact they make up a third of those housed by the learning disability service. The rest, of course, was lovely - quality client-centred services.

They too have a staircase, much more elegant but potentially more lethal. Only one of their number can get down it unaided and none can manage the fire escape. What have they got at the foot of the stairs? A brand new tumble dryer. Many are incontinent and as has been shown in far flung places such as Albania, the arrival of a tumble dryer makes a major difference to the observed happiness of the incontinent. This one came in September. It has never been plugged in. Oh yes, the works department came as they had to put up the framed copy of the Patients' Charter. Someone was very insistent that this little group should not miss out on the Patients' Charter as they sent 1,956 copies. Only one of the 24 has ever been able to read, but no longer since she lost her good eye. Telephone calls have produced promises that it will be done by the end of the week but five months have passed despite many such promised ends to the week.

The Health Advisory Service founded after Ely is no longer interested in people with learning disability, mental handicap or any other label. The National Development Team only comes at the invitation of the Chief Executive. The medical students provide cheer to patients and exhausted nursing staff alike.

Ann Gath, Professor, Department of Developmental Psychlatry, St Margaret's Hospital, Epping. Essex CM16 6TU 